\title{
Socioeconomic impact of drought and desertification on rural livelihoods in the area between Omdurman and west White Nile State, Sudan
}

\author{
Hamza Abdelrefea Magboul ${ }^{\text {a* }}$, Ali Abdel Aziz Salih ${ }^{\mathrm{b}}$, Yahya Hassan Eltayeb ${ }^{\mathrm{C}}$, \\ a, Higher council for Environment. Khartoum, Sudan \\ b, Department of agricultural, faculty of Agricultural, University of Khartoum \\ c, National center for Research, Khartoum, Sudan
}

\begin{abstract}
The objectives of this study were to assess the effects of desertification on rural livelihoods of communities in the area between Omdurman and west White Nile State (Kosti and Elduiem areas). This area was selected to capture three climate change vulnerable ecological zones, namely the desert, semi-desert, and low rainfall savannah area. Primary data were collected by a structured questionnaire by 309 respondents from 12 villages in eight localities selected by a multi-stage stratified random sampling method to obtain the socio-economic parameters. The socio-economic analysis results depicted the prevalence of poverty among $60 \%$ of the study population, relatively considerable dependence on traditional rain-fed agriculture among 55\%, and similar dependence on one crop grown by 58\%. Only a few, (29\%) of the population depended on irrigated agriculture, which reflects the vulnerability of the rural livelihood in the area. However, to expand their crop production, about 49 percent of the vulnerable households adapted their cultural practices applying modern inputs using chemical pesticides and fertilizers, and about $27 \%$ expanded on land cultivation. About $20.5 \%$ changed their crop varieties and about $54.2 \%$ cultivated vegetable crops to earn higher returns. The study recommended the involvement of the government in establishing a rural community association supporting them in combating desertification provision of alternative sources of energy, improve water harvesting systems, conserve, and establish shelterbelts.
\end{abstract}

Published by IJRP.ORG. Selection and/or peer-review under responsibility of International Journal of Research Publications (IJRP.ORG)

Key words: Desertification; Drought; Livelihoods; Socio-economic: coping strategies; impact .

\section{1- INTRODUCTION}

According to the United Nations Conference on Environment and Development (UNCED 1992)

"Desertification is land degradation in arid, semi-arid and dry sub-humid areas resulting from various factors, including climatic variations and human activities".

Desertification is considered Sudan's most significant environmental problem, which lies within a region where desertification threats are high. The region at risk of desertification lies between latitudes 130 and 180 $\mathrm{N}$, extending from east to west across the country, covering a total area of 65 million ha (UNEP, 2007). 
Sudan has been exposed recently to a series of recurring dry years and droughts. Farmers in western, central, and eastern Sudan, whose livelihoods are exposed to the severity of drought and rainfall variability, are the most vulnerable people. Over ten million people were affected by drought in Sudan between 1971 and 2001. In 2000, drought depleted food supplies and led to a three-fold increase in prices relative to the same time in the previous year (Zakieldeen, 2007).

During the last three decades, the White Nile State suffered successive droughts, resulting in recurrent crop failure, deterioration of rangeland, dried up surface water, significant loss of livestock, and families in the states' irrigated agricultural system in Gezira and Khartoum were forced to move to the urban region. Drought-related desertification is seen as a real problem, interfering with the livelihoods of local communities, particularly social stability and food security. (Gaiballa and Farah, 2004).

Omdurman area located in Khartoum state, The state of Khartoum is listed as one of the 13 states affected by drought and desertification in Sudan (Salih, 1996).

The severe cutting of natural forests is among the causes of desertification in the White Nile Province. Wind erosion and shifting sands resulted from over cutting and expansion in rainfed agriculture. Desertification in the state of the White Nile has resulted in canal sedimentation and sand field coverage decreased crop area and low productivity, which has reduced tenant income and resulted in food deficiency and unsustainable growth in the area (Eisa, 2004).

\section{2- Research objective}

The main goal of this study is to investigate the socioeconomic impacts of desertification in Omdurman, Kosti, and Eduiem area. While the specific objectives of the study were to identify the socio-economic characteristics of the households in the study area, assess the desertification effects on agriculture and animal production, and coping strategy to desertification impact.

\section{3- Methodology:}

\subsection{The study area:}

The study area extended along White Nile state from Omdurman in North to Kosti area in the south, it lies between latitudes $11^{\circ} 55^{\prime}$ and $16^{\circ} 48$ north, and longitudes $30^{\circ}$ and $33^{\circ} 15^{\prime}$ east. The study area covers areas in three rural areas, Omdurman area (Omalgora, Fatasha, Algalbab, Adishinap) in the Khartoum state, Kosti (Alfegerab, Alshwafa, Alsabah, Alfaga) and Elduiem area (Alsaada, Wadgber, Alkalagy, Alshatawi) in the White Nile state (figure 3-1). Ecologically the study area extended through the desert (Omdurman area), semidesert (Elduiem) and low rainfall savannah (Kosti area) (Table 3-1).

\section{2. data collection}

The questionnaire was used in this study to collect the primary data. For basic information at the household, the level was designed before the fields work to collect both qualitative and quantitative information. The 
questionnaire was first tested in the field with 10 heads of households. The questionnaire was adequate and very slight modifications were made to suit the conditions of the study area. The interviews were accompanied by personal observations which allowed the researcher to judge the reliability of the answers given. The data were collected in 2017.

A multistage sampling technique was used in the selection of respondents. First, 12 villages were randomly selected from 9 localities, falling in three ecological zones (table 3.1). Second, the household heads were selected randomly, with a sample size representing about 0.018 of the locality population. The household number has been selected from the villages. Thus 309 households across the study area were questioned and interviewed (figure 1). Calculation of the percentage was used as a tool of analysis for interpreting the qualitative information gathered from respondents.

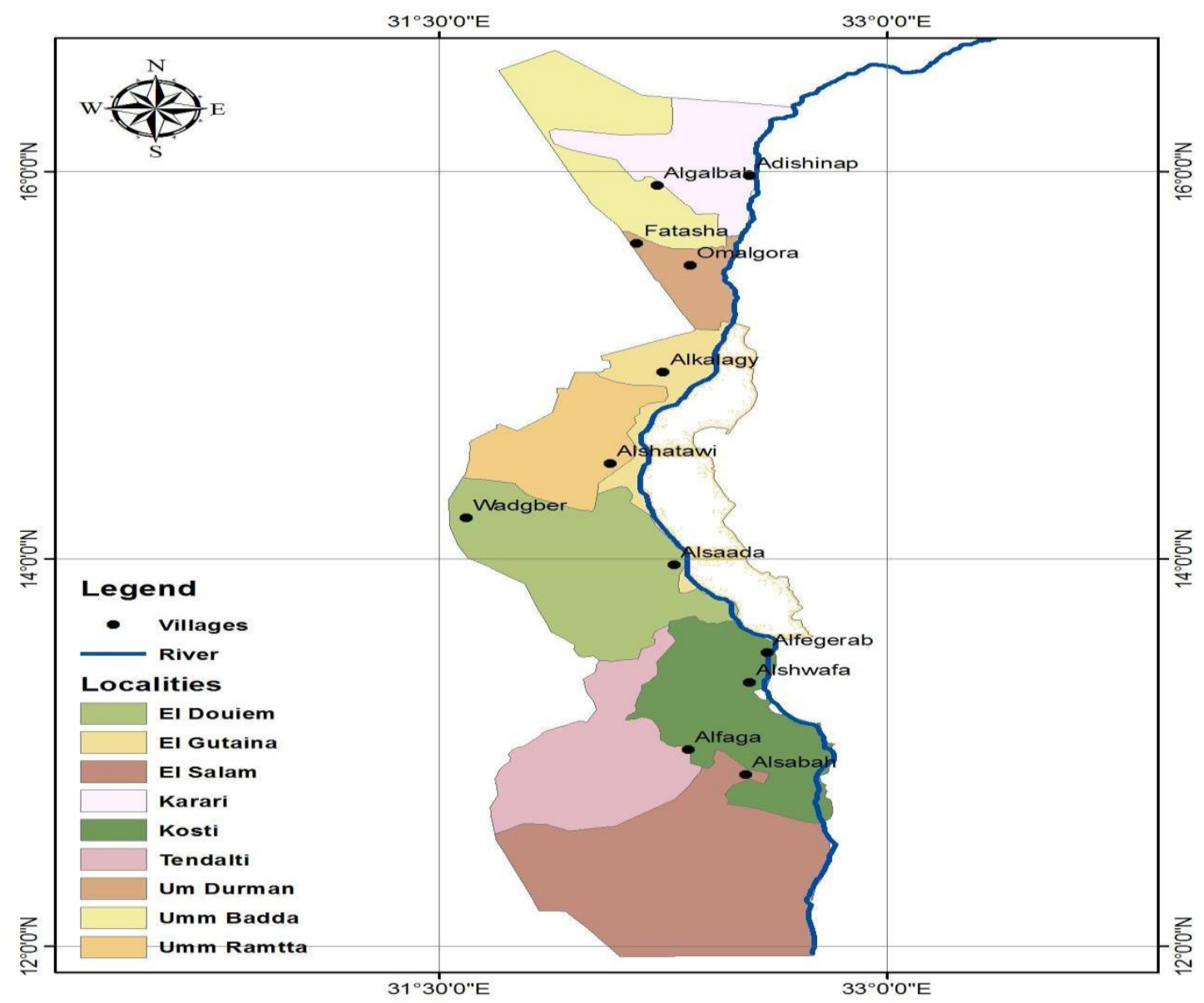

Figure (1) map of villages and localities covered by field survey. 
Table (3.1) the ecological zone of the study area

\begin{tabular}{llll}
\hline Ecological zone & Rainfall & $\begin{array}{l}\text { Desertification } \\
\text { classes }\end{array}$ & Latitude \\
\hline Desert & $1-100 \mathrm{~mm}$ & Desert & $14-18^{\circ}$ \\
Semi-desert & $100-300 \mathrm{~mm}$ & Very severe/severe & $13-14^{\circ}$ \\
Low rainfall savannah & $300-800 \mathrm{~mm}$ & moderate & $12-13^{\circ}$ \\
\hline
\end{tabular}

Source: Salih, 1996

4- Results and Discussion

\subsection{The Socio-economics of the Households}

Age, family size, and education

Most of the households, about 40\%, had ages ranging between 40 and 60 years old in three areas. About $44 \%$ have family size composed of 5-9 members and 55.3\% had formal education (Table 4.1).

The result indicated the experience, responsibility, and capacity of the households to deal with crop and livestock production and coping with the adverse effect of desertification. The family size may be negative or positive in coping strategy, negatively by an increase in the number of dependents and expenditure of life and positive by an increase in the labor force and increase income. The education was still not high enough among the respondents to adopt new technologies and development of crop and animal production and to be aware of Desertification problems.

\section{Occupation of household heads}

Work in agriculture is an important activity to earn money for most of the respondents as a main and secondary job in all areas, about $66 \%$ were farmers. About $55 \%$ in Omdurman their main job is off-farm jobs (table 4.1).

This result indicated that agriculture besides animal-rearing dominated activity between the people in the study area, and most of the respondents have a secondary job to fill the income gap and diversify income. In the Omdurman area, the respondents depend on the off-farm job, this attributed to work in the Khartoum city is better to cope with climate change and practice agriculture as secondary jobs.

\section{Migration in the study area}

Most of the respondents, about 64\%, migrated from their villages for a long or short period during their life for improving their life in the three areas (Table 4.1). This means that the migration considered as one of adaptation and coping strategies to face drought impacts and poverty spread in the study area

\section{Energy sources in household}

The most important source of energy used in the study area was wood, charcoal, and gas, about $52 \%$. The households depend mainly on gas reaching $27.8 \%$, most of them in the Omdurman area. The dependence on charcoal and wood means that the people in the study area depend directly on the natural resources and may 
be affected by deforestation and lack of vegetation cover surrounding their villages. In the same time these coping strategies lead to an increase the desertification.

\section{Income of households}

Table (4.1) showed that most of the households, about 37\%, of total income from agriculture. About $34 \%$ of the total income from animals and $29 \%$ of income from non-farm activities. About $41 \%$ of households income in the Omdurman area from non-farm activity. In the Kosti area about $45 \%$ of income from farm activities and about $61 \%$ of income in the Elduiem area from animals. Dependence on farming and animal made the household vulnerable to drought, while dependence on non-farm increases the chance to cope with droughtlike in Omdurman. Omdurman off-farm attribute to nearest to Khartoum (the capital). The income in Omdurman was higher than in other areas. Most of the households, about $60 \%$ were under the poverty line according to the World Bank, had income less than 20,000 SD equal to about one dollar per person per day (dollar=8.5 SD). About $42 \%$ of respondents in the Omdurman area had income less than 20,000 SD. In the Kosti area, about $71 \%$ and about $60 \%$ in the Elduiem area had income less than 20,000. The respondent in three areas spend their income on basic needs like food. Most of the respondents were under the poverty line, this agrees with IFAD (2010).

Table (4.1) Distribution of household heads (\%) according to demographic characteristics age by villages and areas

\begin{tabular}{|c|c|c|c|c|c|}
\hline \multicolumn{2}{|l|}{ characteristic } & Whole sample & Kosti & Edueim & Omdurman \\
\hline \multicolumn{2}{|c|}{$40-60$} & 40.8 & 31.4 & 51.4 & 40.3 \\
\hline \multicolumn{2}{|l|}{ Family size $\quad 5-9$} & 44.3 & 44.6 & 45.9 & 41.6 \\
\hline Education & Formal education & 55.3 & 64.5 & 48.6 & 50.6 \\
\hline \multicolumn{2}{|l|}{ Main job } & 65.7 & 81.8 & 67.6 & 37.7 \\
\hline \multicolumn{2}{|c|}{ Other jobs } & 30.1 & 15.7 & 28.8 & 54.5 \\
\hline \multirow{2}{*}{$\begin{array}{l}\text { Secondary jobs } \\
\mathrm{n}\end{array}$} & Farmer or animal-rearing & 41.4 & 28.9 & 36.0 & 54.6 \\
\hline & non-farm jobs & 31.1 & 47.1 & 29.7 & 22.1 \\
\hline \multicolumn{2}{|l|}{ Migration } & 64 & 63.4 & 59.8 & 70.6 \\
\hline \multirow[t]{2}{*}{ Energy for cooking } & g Charcoal or wood+ gas & 52.3 & 31.4 & 36.9 & 70.6 \\
\hline & Gas & 27.7 & 14.9 & 35.1 & 27.3 \\
\hline \multirow[t]{2}{*}{ Water sources } & Wells & 62.1 & 53.7 & 77.5 & 67.5 \\
\hline & Water Network & 26.2 & 46.3 & 0 & 32.5 \\
\hline \multirow[t]{3}{*}{ Income source } & Farm & 37 & 11 & 42 & 45 \\
\hline & Animal & 34 & 61 & 29 & 14 \\
\hline & nonfarm & 29 & 27 & 29 & 41 \\
\hline \multirow[t]{3}{*}{ Total income } & $<20.000$ & 59.9 & 71.1 & 60.4 & 41.6 \\
\hline & $20.000-40.000$ & 22.3 & 17.4 & 19.8 & 33.8 \\
\hline & $>40.000$ & 17.8 & 11.6 & 19.8 & 24.7 \\
\hline
\end{tabular}


Depend on traditional agriculture besides rearing animal and migration coping strategies dominated to face desertification, this result agrees with Abu sin. (1986). Most of the respondents live under the poverty line, this agrees with IFPRI (2012); IFAD (2010).

\subsection{Effect of desertification on Agriculture production}

\section{Distribution of households by type of Agriculture:}

Table 4.2 indicated that about $55 \%$ of the total sample in Kosti, Elduiem, and Omdurman grow crops under the traditional rainfed system, $29.8 \%$ irrigated, and 15\% a combination of rainfed and irrigated system. Most of the rainfed concentrated in Kosti, about 70\%, followed by Elduiem, about 50\%, and finally, in Omdurman, about $45 \%$.most of irrigated household concentrated in Omdurman, about $40 \%$, followed by Elduiem, about $37 \%$, and finally by Kosti, about $14 \%$ (table 4.2 ).

The result revealed that grow crops under traditional agriculture are exposed to drought, and those hou seholds who grow the irrigated crop are threatened by sand dune creep and desertification. Hence the effect of drought and desertification in the area affects both households in the rainfed and irrigated crop cultivated system.

\section{Distribution of the household by the size of land}

Table (4. 2) indicated that size of the total sample in the three areas of Kosti, Elduiem, and Omdurman had the land size of more than 10 feddans per household under traditional rainfed agriculture, the table also shows that $61 \%$ of the households had irrigated land less than 5 feddans, in Elduiem area about $44 \%$ of the household had irrigated land more than 10 feddans.

This result reveals that the agricultural land is limit mainly the irrigated land (fertility soils) which had negative effects in agriculture production and adaptation practice to desertification.

\section{Crops in the study area}

About 58\% of the farmers cultivate one crop, mainly in Omdurman, About 79\% (table 4.2). The important crop in the area are sorghum, millet, sesame, and groundnut grow in the rainfed system. A higher percentage of farmers cultivate groundnut, sorghum, and sesame in the Kosti area compare to Elduiem and Omdurman. Millet is the main crop in Omdurman in rainfed agriculture (figure 2). The vegetable is an important crop for diversifying income. About $54.2 \%$ of farmers in all study areas cultivated vegetable crops besides the main crop. All farmers have cultivated watermelon in rainfed agriculture (Table 4.2).

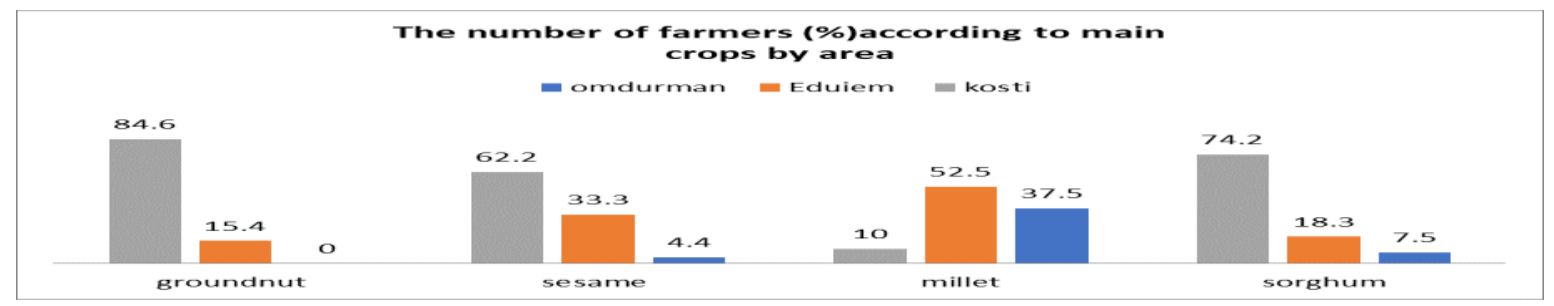

Figure (2) numbers of farmers (\%) according to main crops. 
Moreover, most of the households are vulnerable to desertification impacts as they depend on one crop. There was a change in crop structure in the study area by more dependence on vegetables. The vegetable has a good demand in the cities and this increases the chance of coping with desertification. The millet is an adaptable crop to grow in Omdurman by some farmers, where the rainfall is limited. This led to an increase in desertification.

\section{The crop yield}

About $24 \%$ of the total sample had been exposed to crop failure in sorghum in the rainfed system, about $22 \%$ in millet during agriculture season 2013/2014, and less percentage in sesame and groundnut. Most of the farmers produce less than 3 sacks per feddan of sorghum in rainfed agriculture, about $70 \%$. About $52 \%$ of farmers had a yield of sorghum in irrigated agriculture between 5-10 sacks per feddan. Most of the farmers yield in millet, sesame and groundnut is less than one sack per feddan (table 4.2).

This result reveals that most of the framers suffer from crop failure in the rainfed crop as a result of rain variation. The productivity of crops is very low in the study area, which affects their adaptation.

Table (4. 2) Distribution (\%) of households according to agriculture type, and size and crop yield in areas

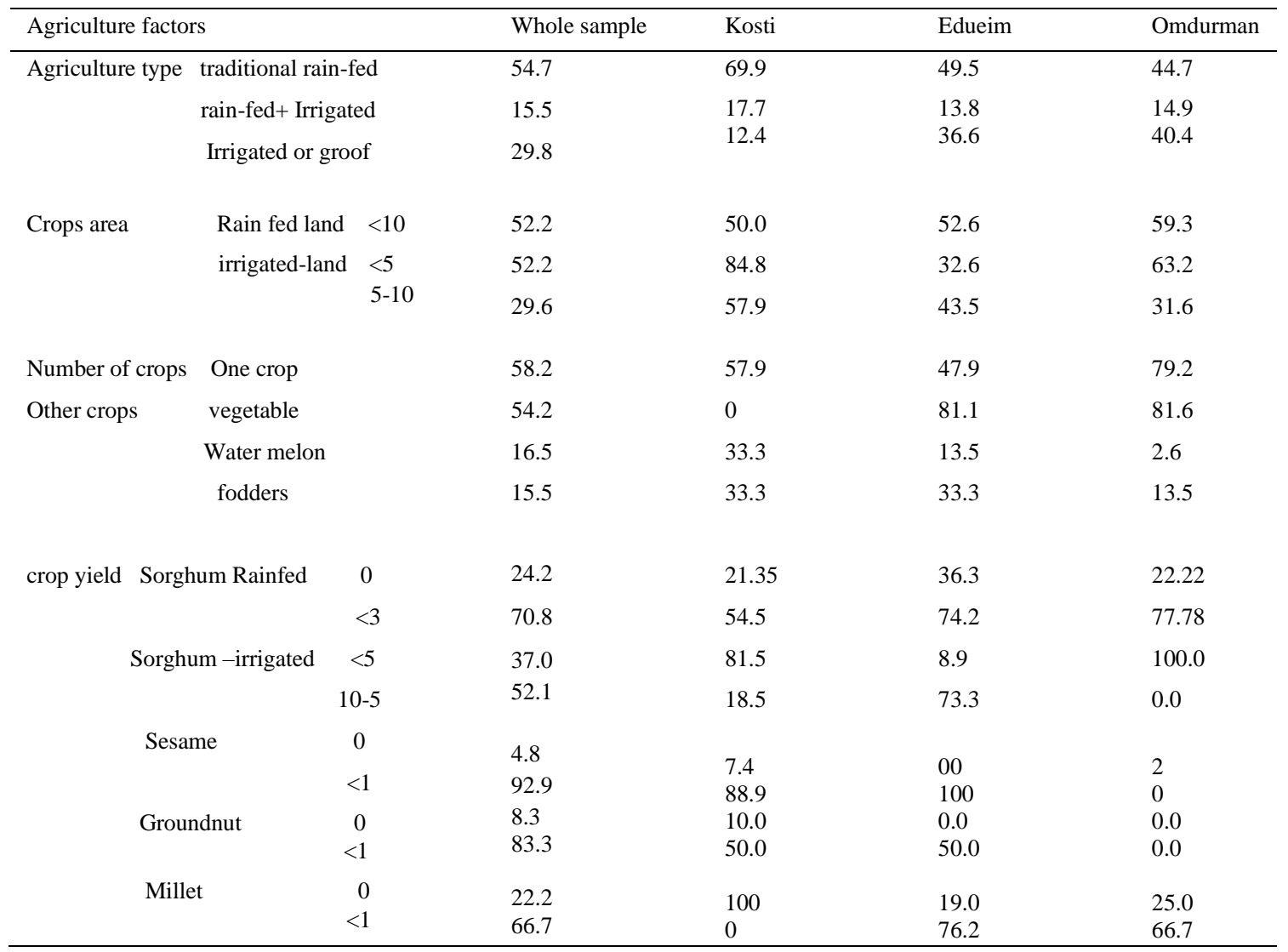




\subsection{The problems of crop production}

Table 4.3 indicates that rainfall variability (drought) was the principal constraint to crop production in the study area. Different reasons were given which include irrigation problems, desert creeping and the pests. Few mentioned that economic factors were also additional reasons. Drought impact on crop production was mainly seen in Omdurman and Kosti area. Pests were severe in Kosti. Irrigation and economic factors of crop production seemed as a reason for the deterioration of crop production in the Eduiem area. Soil deterioration and desert creeping deteriorated crop in the Omdurman area and Eduiem area.

This result indicated that drought is responsible for crop deterioration directly through drought and indirectly through desert creeping and pests.

\section{Coping strategies to deal with crops deterioration}

Most of the respondents use pesticide and fertilizers (48.9\%), 27.4\% expanded the agriculture land and $20.5 \%$ changed their crops to deal with the decrease the agriculture productivity (table 4.3).

In the Kosti area, about $48.3 \%$ of households expanded their land, 15.7\% used pesticide and fertilizers. Only $7.9 \%$ practice other jobs. Eduiem farmers used pesticides and fertilizers to increase agriculture production (66.3\% of household) and $17 \%$ expand their land or change the crops as cope strategy to deal with weak agriculture production. Use of pesticide and fertilizers are the main strategy to deal with weak production in Omdurman area, which about $84 \%$ of respondents (table 4.3 ).

It may be concluded that, farmers use fertilizers and pesticides mainly in irrigated agriculture, which support them to face climate change. The rainfed farmers are more vulnerable to climate change. Without support, they expand on the land or change the crop. The expansion over land leads to clear the land from trees and vegetation cover increase the desert creeping, thus deepening the climate change problems in the area.

Only in the Omdurman area, a high percentage of respondents depend on fodder and this attributes to the high shortage on the rangeland (table 4.4).

Table (4. 3) Distribution (\%) of households according to agriculture problem and coping strategies

\begin{tabular}{llllll}
\hline Characteristic & & Whole sample & Kosti & Edueim & Omdurman \\
\hline Agricultural problems & Drought & 35.4 & 43.1 & 18.0 & 46.7 \\
Desertification & & 21.9 & 11.1 & 26.2 & 33.3 \\
Pest & 20.2 & 29.2 & 18.0 & 11.1 \\
other reason & 10.1 & 6.9 & 19.7 & 6.6 \\
Irrigation problems & & 22.1 & 9.7 & 18.0 & 2.2 \\
Deal crops deterioration & Use pesticide \& Fertilize & 48.9 & 15.7 & 66.3 & 84.2 \\
$\begin{array}{l}\text { Expansion land } \\
\text { change crop }\end{array}$ & 27.4 & 48.3 & 16.3 & 5.3 \\
\hline
\end{tabular}




\subsection{The effect of desertification and drought on livestock}

About $56 \%$ of households have goats, $24.8 \%$ have cows and $19 \%$ have sheep of the total sample in Kosti, Elduiem, and Omdurman. Most of the households, about 49\%, had animals ranged between one to five cows. About $54 \%$ have animals ranged between 1-5 goats and 49\% had more 10 sheep of the total sample. Most of the households in Omdurman, about 50\%, have sheep more than 10 sheep. In Elduiem about 58\% have animals ranging between 1-5 sheep. About 42\% in Kosti has sheep ranged between 1-5 sheep (Table 4.4).

The number of animals decreases overall areas, about $78 \%$ of respondents report that. The drought is the main reason for animal decrease; about $27 \%$ said that, followed by a rangeland shortage, about $26 \%$, which happen by drought (Table 4.4). The majority of respondents depend on rangeland with other sources like agriculture and fodder to feed their animals, this means the rangeland is not enough to feed the animal in the dry season from March to May.

Table (4.4) Distribution (\%) of households according to animal production factors

\begin{tabular}{|c|c|c|c|c|c|}
\hline characteristic & & Whole sample & Kosti & Edueim & Omdurman \\
\hline \multirow[t]{10}{*}{ Animals number } & cows & 24.8 & & & \\
\hline & $1-5$ & 49.2 & 47.5 & 40.0 & 100 \\
\hline & $6-10$ & 22.0 & 22.5 & 26.7 & 0 \\
\hline & Goat & 56.5 & & & \\
\hline & $1-5$ & 54.1 & 62.0 & 47.1 & 52.9 \\
\hline & $6-10$ & 30.6 & 27.6 & 38.6 & 25.5 \\
\hline & Sheep & 18.7 & & & \\
\hline & $1-5$ & 31.9 & 42.1 & 58.3 & 30.0 \\
\hline & $6-10$ & 18.8 & 21.1 & 16.7 & 20.0 \\
\hline & $<10$ & 49.3 & 36.8 & 25.0 & 50.0 \\
\hline \multirow[t]{3}{*}{ Animal } & increase & 16.3 & 12.4 & 26.6 & 10.9 \\
\hline & Decrease & 77.9 & 77.5 & 71.9 & 85.5 \\
\hline & constant & 5.8 & 10.1 & 1.6 & 3.6 \\
\hline \multirow[t]{5}{*}{ Animals Decrease } & shortage of rangeland & 25.5 & 30.0 & 17.4 & 28.3 \\
\hline & disease and death & 12.7 & 11.7 & 17.4 & 15.1 \\
\hline & drought & 27.4 & 20.0 & 26.1 & 35.8 \\
\hline & sell animal & 24.0 & 31.7 & 23.9 & 17.0 \\
\hline & high cost & 8.3 & 6.7 & 15.2 & 3.8 \\
\hline \multirow[t]{3}{*}{ Feeding animal } & rangelands & 7.0 & 14.1 & 5.2 & 0.0 \\
\hline & Fodders & 12.2 & 4.2 & 3.4 & 31.0 \\
\hline & $\begin{array}{l}\text { Rangeland + agriculture } \\
\text { residual }+ \text { fodder }\end{array}$ & 80.8 & 81.7 & 91.4 & 68.9 \\
\hline
\end{tabular}




\section{Conclusions and Recommendations}

\subsection{Conclusions}

Most of the respondents were suffer from desertification, since most of them depend on one crop in rainfed agriculture, and have limited number of animals suffering from shortages of rangeland. Crop productions depend on unreliable rainfall and expanding in land affected by desert creeping which reduced their productivity. The study area suffers from a shortage of food, water, absence of animal and agriculture services, with no shelter belt to protect the crop from desertification. Most of the respondents were vulnerable and the adaptation method was not adequate to mitigate recurrent drought and desertification.

\subsection{Recommendation}

Combating desertification, through the provision of alternative sources of energy, improve water harvesting systems, conserve and establish shelterbelts, cultivate adaptive crops varieties and rear adaptive animals, practice agriculture in an adequate environment. Expanding in irrigated agriculture and rehabilitating the existing projects, and mix animals in these projects.

\section{References:}

Abu Sin, M.H.(1986). "Man's socio-economic response to drought in the White Nile " in : Davies, H.R. J. (edit) : Rural Development in White Nile, Sudan, United Nations University, Tokyo. (www.unu.edu).

Eisa .Adil .Y.Yagoub. (2004). Impact of Environmental Degradation and poverty on Food Security: " Case study of White Nile State, Sudan" M. Sc. Thesis in Agricultural Economics, University of Khartoum.

Gaiballa, A. K., and Farah, A. M. (2004). A Proposed Plan for Research in Desertification in Sudan: White Nile State: in Proceeding of the National

IFAD,(2010). SUDAN Environmental and Climate Change Assessment ., Prepared for IFAD's Country Strategic Opportunities Programme 2013-2017.

IFPRI (International Food Policy Research Institute). (2012). East African Agriculture and Climate Change: A comprehensive analysis -Sudan

Salih, E. M. (1996). The Geographical Extent of Desertification in Sudan.ALBUHUTH J .Sc, Vol. S.pp.18_40.

UNCED. (1992). United Nation Conference on Environment and Development.Chapter 12, Agenda 21. Report of the United Nation Conference on environment and Development. Rio de Janeiro3-14 of June. A/CONF.151/26 (Vol. I) 
UNEP.(2007). Sudan Post-Conflict Environmental Assessment. United Nations environment programme, Geneva.

UNEP and ICRAF. (2006). United Nations Environment Programme (UNEP) and World Agroforestry Centre (ICRAF)(2006), Climate Change and Variability in the Sahel Region: Impacts and Adaptation Strategies in the Agricultural Sector.

Zakieldeen, SA. (2007). Vulnerability in Sudan. Tiempo Bulletin 62. Online bulletin at: www.tiempocyberclimate.org

Zhang, Z., C.-Y. Xu, YONG B, HU J , and SUN Z .(2012). Understanding the Changing Characteristics of Droughts in Sudan and the Corresponding Components of the Hydrologic Cycle. Journal of 